\title{
Finescale Evaluation of Drought in a Tropical Setting: Case Study in Sri Lanka
}

\author{
BRADFIELD LYON AND LAREEF ZUBAIR \\ International Research Institute for Climate and Society, The Earth Institute at Columbia University, Palisades, New York \\ VIDHURA RALAPANAWE AND ZEENAS YAHIYA \\ Foundation for Environment, Climate and Technology, Digana Village, Rajawella, Sri Lanka
}

(Manuscript received 23 April 2007, in final form 5 August 2008)

\begin{abstract}
In regions of climatic heterogeneity, finescale assessment of drought risk is needed for policy making and drought management, mitigation, and adaptation. The relationship between drought relief payments (a proxy for drought risk) and meteorological drought indicators is examined through a retrospective analysis for Sri Lanka (1960-2000) based on records of district-level drought relief payments and a dense network of 284 rainfall stations. The standardized precipitation index and a percent-of-annual-average index for rainfall accumulated over 3, 6, 9, and 12 months were used, gridded to a spatial resolution of $10 \mathrm{~km}$. An encouraging correspondence was identified between the spatial distribution of meteorological drought occurrence and historical drought relief payments at the district scale. Time series of drought indices averaged roughly over the four main climatic zones of Sri Lanka showed statistically significant $(p<0.01)$ relationships with the occurrence of drought relief. The 9-month cumulative drought index provided the strongest relationships overall, although 6- and 12-month indicators provided generally similar results. Some cases of appreciable drought without corresponding relief payments could be attributed to fiscal pressures, as during the 1970s. Statistically significant relationships between drought indicators and relief payments point to the potential utility of meteorological drought assessments for disaster risk management. In addition, the study provides an empirical approach to testing which meteorological drought indicators bear a statistically significant relationship to drought relief across a wide range of tropical climates.
\end{abstract}

\section{Introduction}

Drought is one of the most widespread natural hazards affecting human populations around the globe (Wilhite 2000). Yet no universal definition of drought exists, because the concept fundamentally refers to insufficient water supply relative to a specific demand, both exhibiting considerable geographic and temporal variations. From a hydrometeorological perspective, a number of indices have been developed that emphasize different aspects of drought (e.g., deficient rainfall, soil moisture, or streamflow), on varying time scales, at a particular location (Palmer 1965; Heim 2002; Keyantash and Dracup 2002). The practical use of any of these indices is constrained by the extent to which they cap-

Corresponding author address: Bradfield Lyon, International Research Institute for Climate and Society, The Earth Institute at Columbia University, Palisades, NY 10964.

E-mail: blyon@iri.columbia.edu ture climate fluctuations of relevance to a particular drought-sensitive sector. In addition, such drought indicators need to be sufficiently precise at spatial scales fine enough for administrative responses. The main goal of this paper is to assess the relationship between selected meteorological drought indicators and the occurrence of drought relief payments in a tropical setting, using Sri Lanka as a case study. Drought relief payments made in districts across the country by the government over a 41-yr period will be used as a proxy for drought risk.

Note at the outset the important distinction between meteorological drought, emphasized in this study, and relative dry periods that occur with seasonal regularity in locations with a strong annual cycle of climatological precipitation (e.g., Ropelewski and Folland 2000). Meteorological drought is manifest as a prolonged period (here, $>3$ months) over which precipitation at a particular location is below its climatological, or long-term average, value. In this sense drought is a relative condition, independent of season. 
The drought hazard may be characterized more generally by any of its physical attributes, including deficient rainfall and anomalously low streamflow, as well as the time scale over which such deficits occur (seasonal, annual, or multiyear periods). Drought risk, on the other hand, is determined by both the exposure of human populations to the drought hazard and the vulnerability of a society to drought. Vulnerability varies with the profile of the communities exposed, including their economic activities, infrastructure, and established networks-all of which vary with location. As societies acquire greater resiliency through improved preparedness and mitigation practices, a drought must be more severe to induce a disaster.

The opportunity for a detailed investigation of the relationship between drought hazard and (a proxy for) drought risk arises in Sri Lanka because of the availability of both meteorological and drought relief payment data at relatively fine spatial resolution. Sri Lanka has long records of good-quality meteorological observations (e.g., rainfall) at a large number of stations $(300+)$, providing a dense spatial coverage for an island of roughly $225 \mathrm{~km}$ by $400 \mathrm{~km}$. Various meteorological drought indicators can thus be computed at a fine spatial scale (more on this in section 3). Records of districtlevel drought relief payments in Sri Lanka are also available for the period 1960-2000. Given its range of annual rainfall from between 500 and $5500 \mathrm{~mm}$ and varied seasonality, Sri Lanka also serves as a case study for drought hazard and risk analysis for tropical climates more generally. This extension is not exhaustive, however, because some climate types (e.g., arid regions or where snowmelt is important) are not represented in Sri Lanka.

In this paper, we shall 1) assess the potential use of meteorological drought indices, evaluated at fine spatial scale, as predictors of drought relief payments at the district level, 2) assess the comparative performance of different drought indices in this regard, and 3) assess the performance of these indices in different climatic settings in Sri Lanka. Based on our findings, we shall also draw some inferences for other tropical locations.

\section{The study area}

Although Sri Lanka is prone to multiple natural hazards, drought has historically been the most significant hazard in terms of people affected and relief provided (with the exception of the 2004 tsunami) (Zubair et al. 2006). The country has an area of approximately $65000 \mathrm{~km}^{2}$ and a population of 19.5 million (Department of Census and Statistics 2001). The agriculture, forestry, and freshwater fisheries sectors accounted for
$15 \%$ of the national gross domestic product (GDP) and employed 35\% of the labor force in 2001 (Department of Census and Statistics 2001). The agrarian economy is susceptible to disruption during droughts. The major cash crops by area cultivated (in thousands of hectares) are tea (195), rubber (159), coconut (444), and spices. The primary food crop is rice (739) with coconut of secondary importance. The main Maha rice-cropping season commences with heavy rainfall and typically starts in late September and ends in March. A secondary season, Yala, extends from May to early September. During this second season only about one-half of the total agricultural land is cultivated because of a limited supply of water. Rainfall variations during both seasons have been shown to influence rice and coconut production (Zubair 2002; Peiris et al. 2008).

There is considerable capacity in Sri Lanka to mitigate drought through a system of transbasin diversions, the existence of large storage reservoirs, and over 12000 small village-level reservoirs (Zubair 2005). These reservoirs provide carryover storage from the rains during the main cultivation season commencing in October to the secondary cultivation season commencing in April. These reservoirs do not, however, provide for multiyear storage. Prior to each cultivation season, there is a consultative process among farmers and irrigation managers leading to predetermined schedules of water releases based on storage and anticipated rainfall. Farmers use these estimates to optimize their choice of crops and extent of planting. Thus, even though irrigation works provide some water storage, farmers are unlikely to be able to mitigate the impacts of serious drought (Zubair 2005). Based on detailed field studies in the north, Madduma Bandara (1981) reported that mitigation of drought impacts in the dry parts of Sri Lanka was primarily restricted to relief payments.

Drought impacts are immediate in the agricultural and domestic water supply sectors, and extreme drought events can have an economy-wide impact. For example, planned outages of electricity due to deficits in hydropower generation lead to disruptions in the manufacturing industry and utility services, which account for $25 \%$ of the GDP and $21 \%$ of the labor force. The protracted drought of 2001-02 had severe consequences for public health, agriculture, water supply, and hydropower generation and led to a $1 \%$ drop in the GDP growth rate (e.g., Nexant 2008).

Sri Lanka's location and topography have a strong influence on its climate. The principal topographic feature in Sri Lanka is an anchor-shaped mountain massif in the south-central part of the country, reaching a peak elevation of $2532 \mathrm{~m}$. Climate zones in Sri Lanka have been defined in several ways. The total annual rainfall 


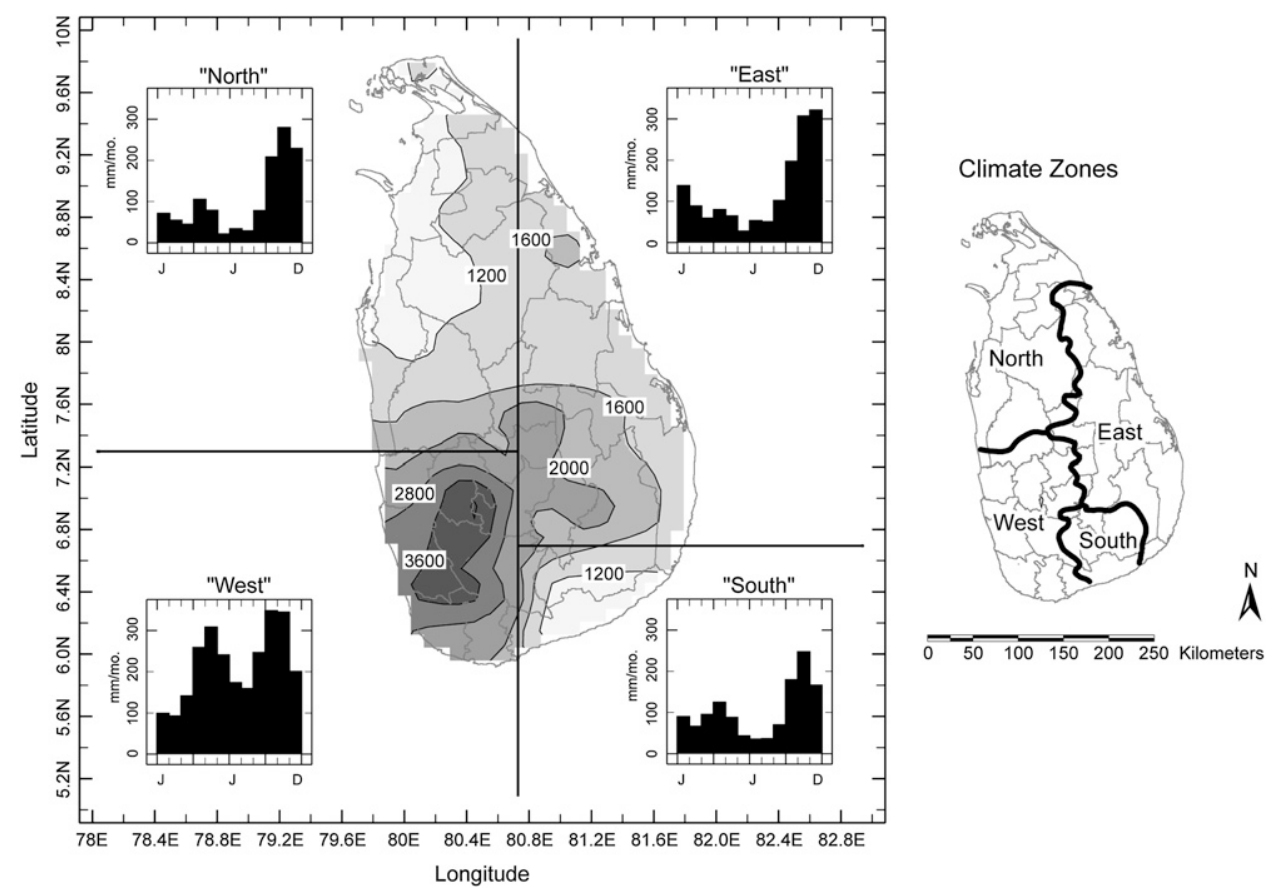

FIG. 1. Average annual rainfall ( $\mathrm{mm}$; shaded) and monthly values ( $\mathrm{mm}$; histograms) for four regions (boxed regions; land areas only) that roughly correspond to the main climate zones identified by Puvaneswaran and Smithson (1993) (their east, west, north, and south climate zones are delineated by the thick black lines on the insert; right). Data within the boxed regions are used for computing area-average correlations in Fig. 2 and drought index values in Fig. 6.

has been used to demarcate the island into three zones representing dry, intermediate, and wet conditions (e.g., Domroes 1978). Further divisions of these zones using temperature and soil types led to 24 subdivisions (Panabokke 1996). Puvaneswaran and Smithson (1993) demarcated the island into four climate zones based on the seasonality of average monthly rainfall. We have used the latter definition here (the four zones are shown in Fig. 1), because it separates out the regions that are subject to orographic influences on rainfall generation during the southwest and northeast monsoons. For example, the "east" (with an area average of $1721 \mathrm{~mm}$ in annual precipitation) and "west" (2462 mm) climate zones garner more rainfall due to orographic influences than the "north" (1158 mm) or "south" (1016 mm).

Annual rainfall is greatest in the southwest of the country (Fig. 1), with a relatively drier climate in other locations (Zubair et al. 2008). With an average annual rainfall of roughly $1800 \mathrm{~mm}$ Sri Lanka may appear unlikely to be significantly impacted by drought. However, the distribution of rainfall through the year varies with region, being strongly bimodal in the west, for example, with peaks occurring roughly in the April-June and October-December seasons. This poses some challenges to drought assessment because deficient rainfall and attendant drought in one season may or may not be compensated for by precipitation in the previous or subsequent season, determining whether a short-lived or comparatively extended drought is played out. In addition, drought may be modulated by rainfall occurring between these dominant rainy seasons.

Relationships between Sri Lankan rainfall and sea surface temperatures (SST) in the Pacific Ocean have been described by Rasmusson and Carpenter (1983), Suppiah (1996), and Zubair et al. (2008). These studies (and several others) point to a strong relationship with ENSO that varies seasonally. Relationships of Sri Lankan rainfall to Indian Ocean SST have been reported by Suppiah (1988), Zubair et al. (2003), and, on interannual to decadal time scales, Suppiah and Yoshino (1984) and Malmgren et al. (2007).

\section{Data and meteorological drought estimates}

\section{a. Precipitation and drought relief data}

Monthly rainfall data covering the period from January 1960 to December 2000 were obtained from the Sri Lanka Department of Meteorology for 22 of its synoptic stations and secondary sources for a total of 284 stations across the country. We subjected the data from the 
synoptic stations to quality-control procedures as outlined by the Global Historical Climatology Network (Peterson et al. 1998) and established that they were reliable for the period 1960-2000 with just a few exceptions. Data from the remaining stations were compared with the quality-controlled Department of Meteorology stations and with nearby stations to identify extreme outliers, transcription errors, and calibration errors. Based on these comparisons, a small subset of stations $(<5 \%)$ was discarded. This database was then utilized to generate gridded drought indices at a spatial resolution of $10 \mathrm{~km}$ using the Weaver interpolation scheme developed at the U.S. Climate Prediction Center. The Weaver analysis scheme is a simplified version of the Cressman (1959) analysis, performing unweighted spatial interpolation without the use of radii of influence. When used to interpolate to an equally spaced latitude/ longitude grid, only observations located within each grid box are used to calculate the interpolated value for that grid box. (At the time of writing, further details on the Weaver analysis scheme could be found online at http://ingrid.ldeo.columbia.edu/dochelp/StatTutorial/ Interpolation/.)

Drought relief payment data at the district level (25 in Sri Lanka, identified in Fig. 3 below) were obtained from the Sri Lanka Department of Social Services, the Sri Lanka Department of Census and Statistics, and the Central Bank of Sri Lanka. Incidences of disasters (here, substantial impacts from drought) are reported through the government hierarchy beginning at the village level, are then aggregated to subdistrict (Divisional Secretariat), and then are further aggregated up to the district level before being reported to both provincial and national disaster management agencies. Over this period, the Ministry of Social Services and its subordinate institution, the Department of Social Services, are charged with monitoring disasters and associated relief payments. Issuance of relief payments is based on the severity of the disaster, on the availability of funds, and on the number of people affected. At the time of issuance, a classification is also made as to whether the disaster is considered to be a minor event, a medium event, or a major event. The Sri Lanka Department of Census and Statistics subsequently records and archives these data. Relief payments are issued from weeks to within a few months of drought impacts. Information on the classification of drought relief payments and affected districts was obtained from the Department of Census and Statistics.

Drought relief payments afford a proxy for drought risk and indicate when and where drought has occurred. Such consistent records for periods extending to 40 years are rare in the tropics. In taking relief payments as a proxy for drought risk, we are assuming that the drought reporting and record-keeping mechanisms described previously are comprehensive through time and that political factors do not alter the distribution of relief significantly. If political and administrative factors were to affect drought relief, then it would compromise the evidence for relationships between meteorological drought and relief payments in the analysis.

\section{b. Meteorological drought indices}

Multiple drought indices are in use (e.g., Keyantash and Dracup 2002), but those presented here were chosen primarily for their computational simplicity. Indices based on variables such as streamflow, vegetation condition, or soil moisture estimates were either not available at adequate spatial resolution or lacked reliability and/or sufficient historical extent for the analysis. All of the meteorological estimates of drought were therefore based solely on monthly rainfall observations across Sri Lanka. These drought indices were initially computed at individual stations and then gridded to $10-\mathrm{km}$ resolution. To take into account spatial variations in climatological rainfall, absolute measures of rainfall variability were avoided in favor of two alternative approaches. In one approach, time series of accumulated monthly rainfall anomalies (departures from a 19712000 base period mean) were assessed for time intervals of $3,6,9$, and 12 months at each station using overlapping, running, sums. These sums were then expressed as a percentage of average annual precipitation at each station to yield indices hereinafter called PRCT-3, PRCT-6, and so on. The percentage of annual precipitation was used instead of subyearly totals to avoid inflated percentages during relatively dry seasons that do not necessarily represent a correspondingly large quantity of water.

In a second approach, the standardized precipitation index (SPI; McKee et al. 1993) was computed at each station for the same time intervals as for the PRCT index, and it will similarly be referred to as SPI-3, SPI-6, and so on. The SPI is computed by using all the historical data available (here 1960-2000) to fit a cumulative probability distribution for rainfall amounts observed over a particular period of interest (e.g., 3, 6, or 9 months). This cumulative probability distribution is then translated to a normal probability distribution with a mean of 0 and standard deviation of 1 . The SPI-3, SPI6 , and so on will thus all have equal probabilities of exceeding a given index value. For example, the probability of the SPI- 6 being $<-1.0$ is the same as that for SPI-3 being $<-1.0$, and so on, because this represents $\operatorname{Pr}(x<-1)$ for a normal probability distribution of $x$ having zero mean and unit variance. 


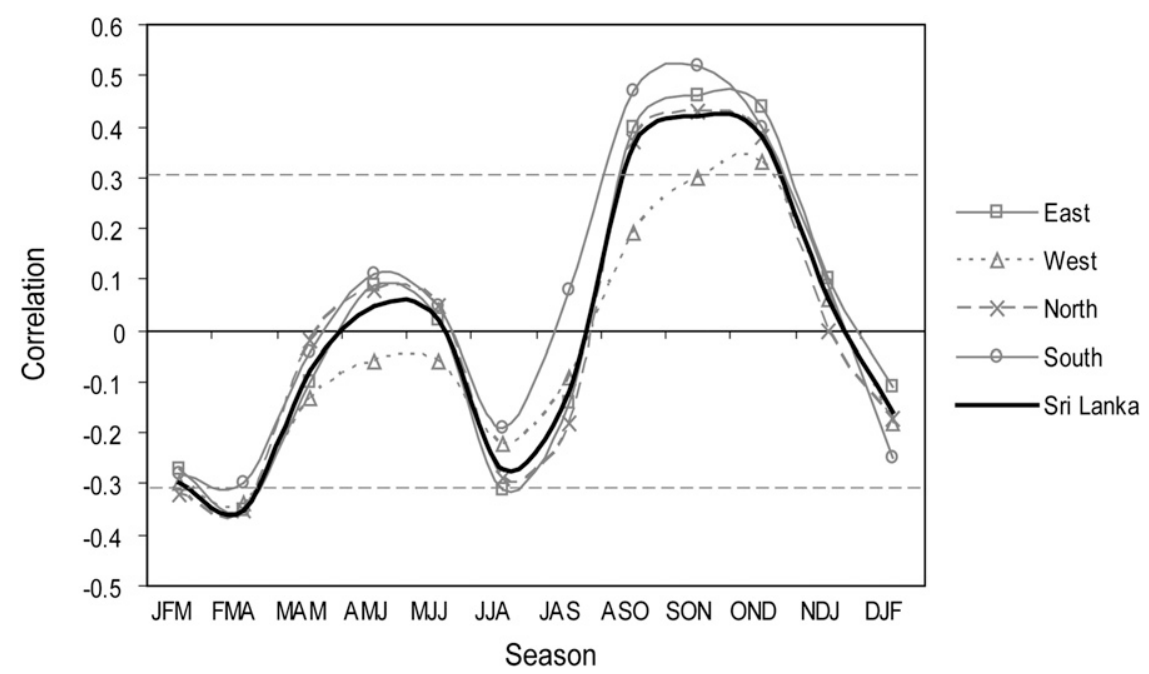

FIG. 2. Temporal correlation (1960-2000) between SST anomalies averaged over the Niño3.4 region and the SPI-3 index averaged over the boxed regions in Fig. 1 and for all of Sri Lanka as a function of overlapping, 3-month season. Statistically significant correlation thresholds $(p<0.05)$ are indicated by dashed horizontal lines.

The periods of 3, 6, 9, and 12 months were selected for both indices to capture rainfall variability on time scales ranging from a single season (i.e., 3-month period) to multiple seasons. As such, these indices cannot fully capture more protracted droughts that last longer than 1 yr. However, many droughts in Sri Lanka are associated with the ENSO, with its cold phase typically leading to anomalously dry conditions from October to December (Zubair et al. 2008). For example, the spatially averaged, temporal correlations between SST (from Smith and Reynolds 2004) anomalies ${ }^{1}$ averaged over the Niño-3.4 region $\left(5^{\circ} \mathrm{S}-5^{\circ} \mathrm{N}, 120^{\circ}-170^{\circ} \mathrm{W}\right)$ and the SPI-3 index are plotted in Fig. 2 for the four regions of Sri Lanka delineated in Fig. 1 as a function of overlapping 3-month seasons. During boreal autumn, statistically significant $(p<0.05)$ positive correlations are seen for all four regions of Sri Lanka, indicating the well-established tendency for warm (cold) ENSO events to be associated with above (below) expected seasonal rainfall during this period (Zubair and Ropelewski 2006). However, the correlations weaken and then reverse sign in all locations of Sri Lanka later in the boreal winter into early spring, with statistically significant negative values observed for the January-March and February-April seasons. Given this seasonally varying relationship with ENSO, temporal correlations between

\footnotetext{
${ }^{1}$ SST anomalies were computed as departures of observed monthly values from the climatological mean for that month computed over a 1971-2000 base period. A 3-month running average was subsequently applied to the time series.
}

Niño-3.4 SST anomalies and longer-term drought indices such as the SPI-24 and PRCT-24 do not reveal any statistically significant relationships (not shown), with corresponding correlations typically not exceeding \pm 0.1 . Factors other than ENSO can also lead to drought in Sri Lanka such as Indian Ocean SSTs (e.g., Zubair et al. 2003), but the role they play has not been explicated fully.

Given the strong seasonality of climatological rainfall in Sri Lanka, a weighted version of the PRCT indices was also examined to test the sensitivity of drought impacts to the timing of rainfall anomalies during a given year. The monthly weights were larger for climatological "wet" months and also take into account monthly rainfall variability at each station to allow for comparisons at locations across the country. The weighted sums used to construct the time series at a given station may be expressed mathematically as

$$
S_{N}=\frac{1}{\overline{P_{A}}} \sum_{i=1}^{N} \frac{P_{i}^{\prime}}{\alpha_{i}},
$$

where $P^{\prime}$ is the precipitation anomaly for the $i$ th month in the $N$-month sum (here $N$ is $3,6,9$, or 12), which has been weighted by the coefficient of variation (standard deviation divided by the mean) of monthly precipitation $\alpha_{i}$, computed over the 1971-2000 base period. As with the unweighted measures, the sum is then expressed as a percent of the annual-average precipitation $\overline{P_{A}}$. The weighting scheme is mathematically equivalent to that used in previous studies of tropical drought by Lyon (2004) and Lyon and Barnston (2005). 


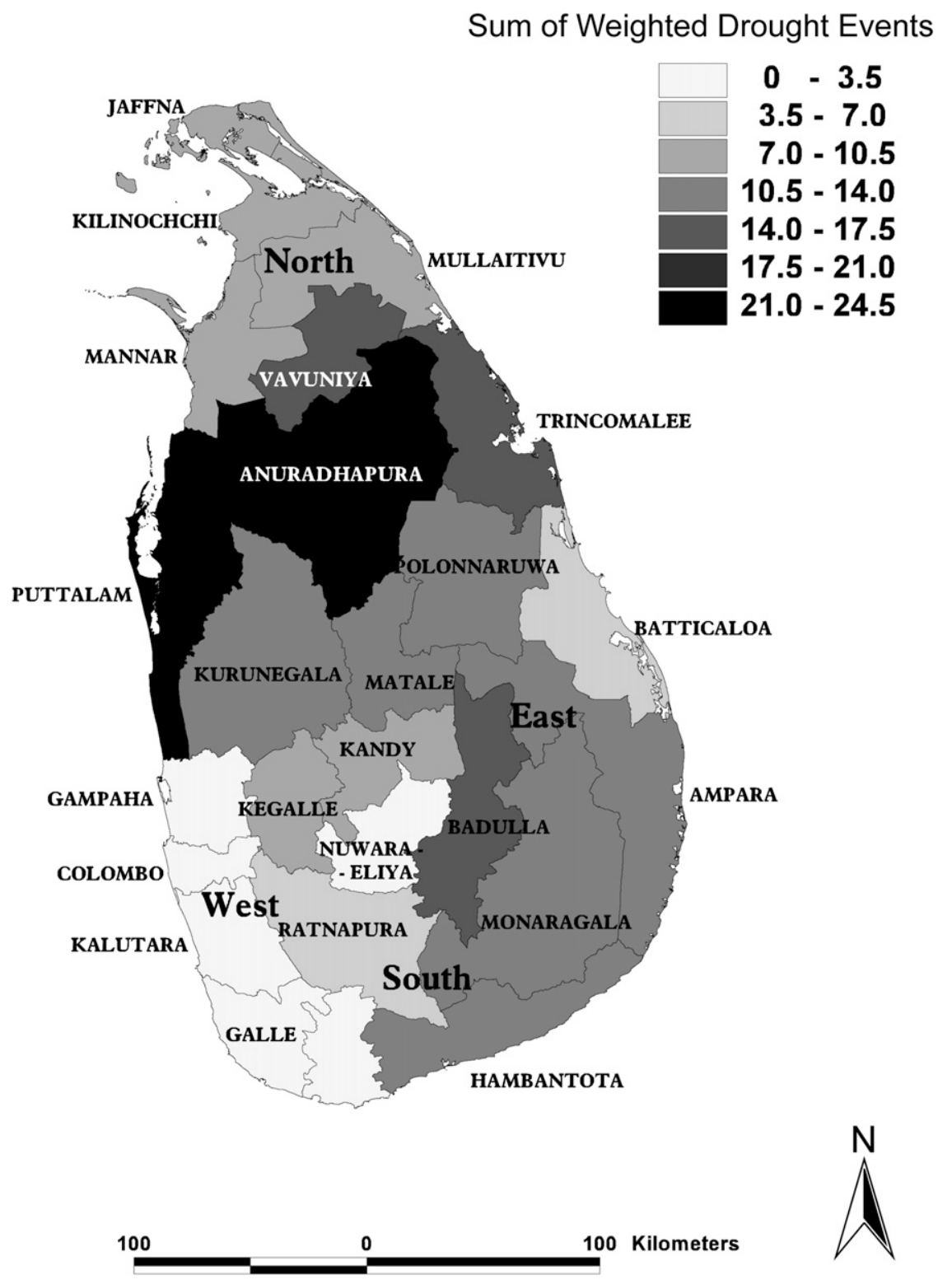

FIG. 3. Proxy drought risk map for Sri Lanka based on the frequency (and size) of historical drought relief payments. The figure was constructed by summing the number of drought relief payments made to each district (1960-2000) after assigning them a numeric value depending on the category of drought as determined by the Department of Social Services. Major droughts are assigned a value of 1.5, medium droughts are given 1.0, and minor droughts are assigned 0.5.

\section{Drought incidence and hazard risk}

\section{a. Spatial distribution}

A drought risk map for Sri Lanka was constructed by summing the occurrence of drought relief payments made at the district level over the study period after weighting individual events according to their severity. Relief payments are thus used as a proxy for drought risk. In terms of severity, the Sri Lanka Ministry of Social Services has categorized each drought (i.e., when relief was provided) as being of minor, moderate, or major severity. We accordingly have arbitrarily assigned weights of $0.5,1$, and 1.5 for the minor, medium, and major droughts, respectively. The results reported here are robust with respect to moderate changes to this weighting scheme. The resultant risk map (Fig. 3) shows marked spatial variability, with relatively low drought risk in the western climate zone and higher risk in the northern, eastern, and southern zones. The highest drought risk occurs in Anuradhapura district (northern 

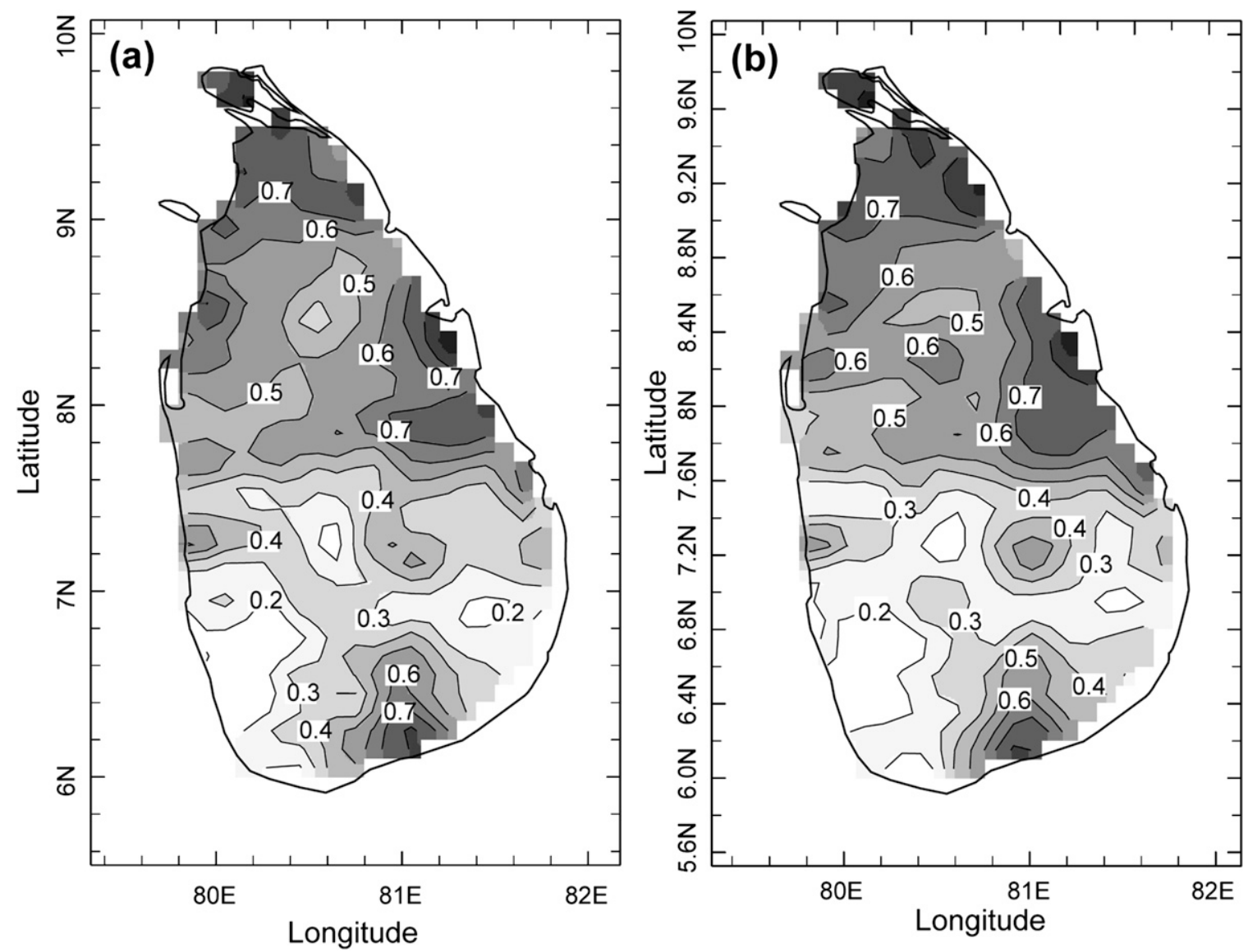

FIG. 4. The relative frequency (normalized to have a maximum of 1) of drought events identified when (a) the PRCT-6 index was $10 \%$ or more below the annual average rainfall for 5 or more consecutive months and (b) the PRCT- 9 index was more than $15 \%$ below the annual average rainfall for 5 or more consecutive months.

climate zone) followed by Puttalam (north), Vavuniya districts (north), and Hambantota district (southern climate zone). Note that northern districts in Sri Lanka have higher relief payments per capita because they are sparsely populated.

How do spatial variations in estimated drought risk compare with meteorological drought occurrence? To answer this question, the spatial variation of meteorological drought was assessed by mapping the relative occurrence of drought "events," identified (at each grid point) when a given drought index exceeded prescribed thresholds of magnitude and duration. Several such analyses were generated based on the PRCT and SPI and various magnitude and duration criteria. Results based on the SPI, for different time periods (not shown), revealed a tendency to have too many drought events (relative to the risk map) in the west and too few elsewhere. A better correspondence to the drought risk map was found using the PRCT-6 or PRCT-9 index to define drought events.
In comparing the drought risk map (Fig. 3) with meteorological drought frequency (Fig. 4), we see several general similarities. Meteorological drought events based on the PRCT-6 and PRCT-9 indices are seen to be less frequent in the southwestern coastal areas of the country (Galle, Kalutara, Colombo, and Gampaha districts in the western climate zone) than in other areas. The hill districts of the western climate zone, including Nuwara, Eliya, and Ratnapura, do however have greater drought occurrence than in the southwestern coastal areas using these measures. There are also some notable differences in the spatial patterns of the two figures. For example, the comparatively high drought frequency in the Trincomalee district in the eastern climate zone and in the Batticaloa, Mullaitivu, and Jaffna districts in the northern climate zone is not reflected in equally high and/or frequent relief payments. Normalizing the number of relief payments by population of each district does, however, bring higher per capita payments in these sparsely populated districts 


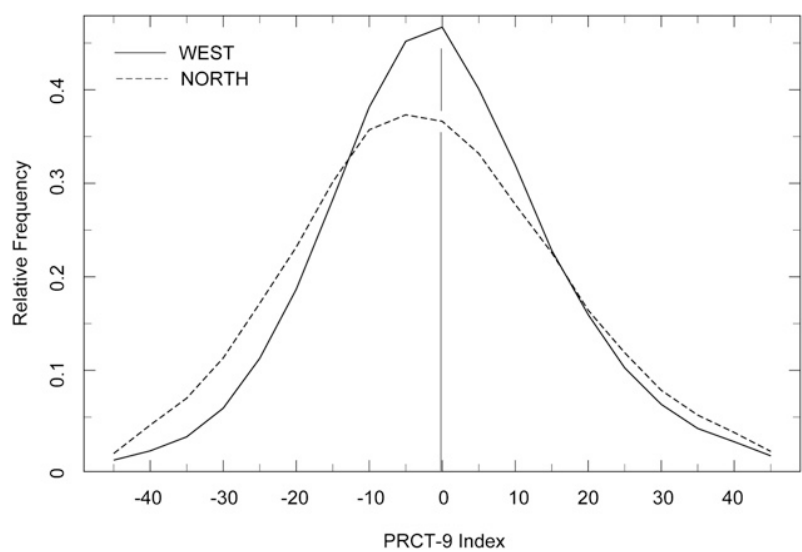

FIG. 5. The pdf (relative frequency) of the PRCT-9 index evaluated for all grid points in the climate zones of the west (solid line) and north (dashed line).

relative to other areas (not shown). In addition, the Anurhadhapura district in north-central Sri Lanka and neighboring Puttalam district appear to garner a substantial number of relief payments in comparison with historical meteorological drought events. If the total number of drought relief payments for these districts is normalized by population, then the rank of these districts is somewhat reduced relative to other areas, but they are still seen as outliers when compared with the relative frequency of meteorological drought events. Among the factors that could be affecting relief payments generally are the percent of the population engaged in agriculture (e.g., coastal districts are likely to have substantial populations engaged in fishing) and the caliber of the government administrative machinery and political clout of each district.

The reasons why the SPI did not capture similar spatial patterns for drought occurrence when compared with the PRCT index were examined in more detail. The differences were found to be related to regionally varying features of the probability distribution function (pdf) of the PRCT index relative to that of the SPI. By design, the pdf of the SPI has a normal distribution with zero mean and unit variance. As mentioned previously, the probability of the SPI exceeding a given index value is therefore the same at all locations. The PRCT index, however, is not similarly constrained, and therefore the probability distribution may vary regionally. Why this should lead to fewer drought events in the west and comparatively more in the north when using PRCT versus SPI can be seen schematically in Fig. 5 in which the pdfs of the PRCT-9 index are shown for both regions. The figure indicates that the probability of the PRCT-9 index being less than approximately $-15 \%$ is greater in the north than in the west because of the greater dispersion in the distribution in the north. Thus, drought events defined using a PRCT-9 index threshold of less than $-15 \%$ have a higher probability of occurrence in the north relative to the west. The result is that the map of meteorological drought frequency (Fig. 4) and the proxy map for risk (Fig. 3) have generally similar spatial distributions when using the PRCT index, with dissimilar patterns found based on the SPI. This result does not imply, however, that fluctuations in the PRCT index will necessarily be more closely related to drought relief payments than the SPI when the climate zones are evaluated individually. In that case, different thresholds of the SPI can be used in each region to determine which has the best relationship to the occurrence of drought relief. This is described in more detail in the next section.

\section{b. Regional drought indicators and occurrence of drought relief}

To compare the regional occurrence of drought relief payments with measures of meteorological drought through time, the relief payment information and drought indices were first aggregated (approximately) to the scale of the four climatologically homogeneous regions. To do this, the occurrence of drought relief payments for all districts within a given climate zone was flagged, generating a binary (yes/no) time series of monthly observations for each zone. Time series of drought indices were then computed as the area average of all grid point values within the rectangular box that most closely fit that climate zone (as delineated in Fig. 1). The drought index time series were detrended to emphasize the interannual variations of interest here. Periods of drought identified in the PRCT and SPI time series were then compared with the occurrence (or nonoccurrence) of drought relief payments over the period 1960-2000. Time series of the PRCT-9 index generally showed the best correspondence to drought relief for each of the four climate zones shown in Fig. 6, where the black bars indicate the occurrence of drought relief within each zone. The length of the black bars in the figure is $0.5,1$, or 1.5 for drought classified as minor, moderate, and major, respectively.

For all four regions, drought relief payments are generally seen during periods with contemporaneous negative drought index values, especially when the index drops below values roughly between $-15 \%$ and $-20 \%$. There are a few cases, however, when drought events developed but relief payments were not made. For example, in all four regions a period of fairly substantial drought occurred in the mid-1970s with no relief payments. During this period, the government was under significant financial stress due to national budget 

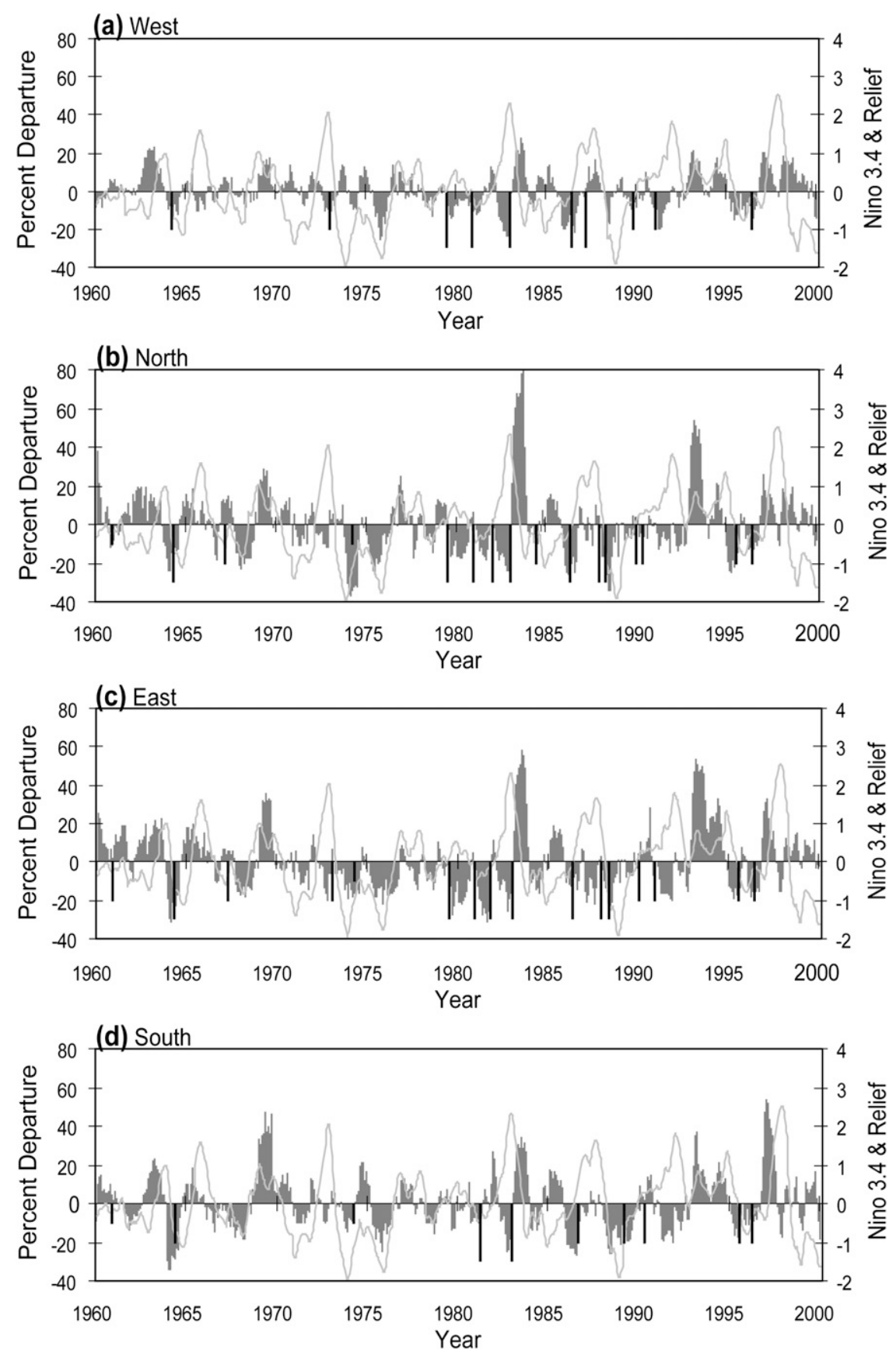

FIG. 6. Time series (1960-2000) of the detrended PRCT-9 index averaged over the boxed regions in Fig. 1 that approximately represent the (a) west, (b) north, (c) east, and (d) south climate zones. Vertical black bars indicate the occurrence of drought relief payments; their length is proportional to the payment amount in three categories $($ major $=1.5$, medium $=1.0$, and minor $=0.5$ ).

deficits (Zubair 2005, and references therein), likely affecting the decision to issue relief payments.

These general associations between meteorological drought occurrence and relief payments were also considered more quantitatively. Results that contrast the dry north with the wet climate of the west are pro- vided here. For this comparison, time series of monthly values of the drought indices averaged over each climate zone were compared with the corresponding, binary time series of the occurrence of drought relief payment for each calendar year and the first 3 months of the subsequent year. Including the first 3 months of the 
subsequent year recognizes that there may be a lag between meteorological drought occurrence and subsequent government relief. Various thresholds of the drought indices were then used to construct $2 \times 2$ contingency tables indicating the occurrence or nonoccurrence of a drought relief payment when a drought index exceeded these thresholds. The contingency table entries for each climate zone were then used to test for statistical significance using the Fisher exact test (Sheskin 2004). The contingency tables were also used to compute several other performance measures for each zone including the 1) hit rate (HIT), 2) threat score (TS), 3) probability of detection (POD), 4) false-alarm rate (FAR), 5) bias (BIAS), and 6) Heidke skill score (HSS) [see Wilks (1995) for more details on these measures].

For the north, statistically significant results were obtained for both the SPI and PRCT evaluated at time periods of between 3 and 12 months. However, based on the various performance measures, statistical significance levels, and testing several drought index thresholds, the strongest relationship $(p<0.01)$ between drought occurrence and drought relief was found for the PRCT-9 index and a threshold of $-15 \%$. Results for the weighted versions of the PRCT indices [i.e., using Eq. (1)] were generally similar to the unweighted results although a somewhat better relationship was found for the weighted version of the PRCT- 3 index in the north, indicating the importance of the boreal autumn rainy season there. For the west, neither the SPI-3 nor PRCT3 showed a statistically significant relationship with drought relief occurrence across a number of drought index thresholds. The closest correspondence in the west $(p<0.01)$ was found using the 6-month PRCT index and a threshold of $-10 \%$. For both the north and the west, the SPI did show statistically significant relationships $(p<0.05)$, but the other performance measures yielded somewhat poorer results when compared with the PRCT index. Sampling issues may have also played a role in this finding. A summary of performance measures based on the PRCT index results is shown in Fig. 7, which uses the abbreviations defined in the previous paragraph.

The overall results suggest that in the dry north relatively short-lived drought events (i.e., those captured by the PRCT-3 index) can cause substantial impacts. It is hypothesized that because the north receives more than $55 \%$ of its annual rainfall during the 3 -month period of October-December deficient rainfall in this single season can be particularly detrimental to agriculture. This was suggested by the closer correspondence between relief payments and the weighted PRCT-3 index and can also be seen in Fig. 8, which shows the monthly distribution of drought relief payments for the full 41-yr study period for both the west

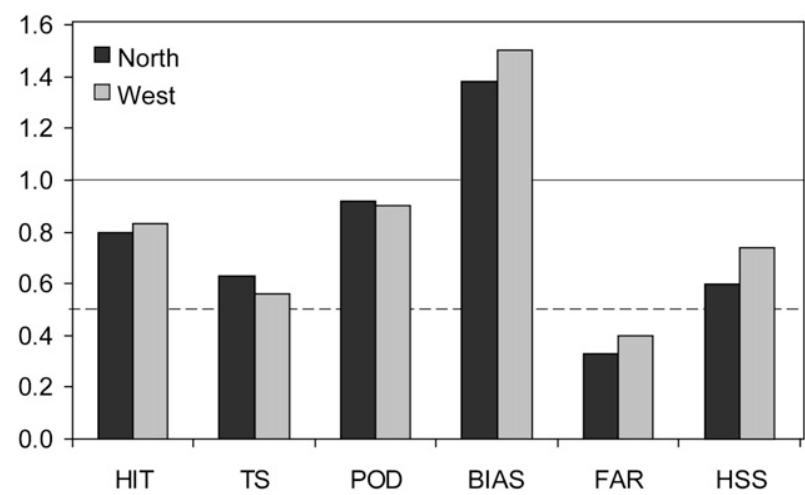

FIG. 7. Predictor performance measures (dimensionless) based on $2 \times 2$ contingency table results using the PRCT-9 index with a $-15 \%$ threshold in the north (dark bars) and the PRCT- 6 index with a $-10 \%$ threshold in the west (light bars).

and north. Two-thirds of the payments in the north occurred after January (Fig. 8a), whereas for the west they were evenly divided between boreal autumn and the subsequent spring seasons. The best overall relationship with drought relief in the north is captured by the 9-month PRCT index, which suggests that the north, while impacted by shorter-lived droughts (e.g., 3 months), is also susceptible to more protracted drought events. In the north there is a high probability of failure of agriculture due to drought from April to September because this is the water-constrained, secondary agricultural season there (Zubair 2002). In the much wetter west, single-season droughts do not appear, in general, to be as detrimental to agriculture as in the more-waterlimited north-in particular, in the April-September agricultural season. This is suggested in Fig. 8 by the overall lower number of drought relief payments made to the west (10, vs 16 for the north).

\section{Discussion and conclusions}

Our work shows that drought events identified by meteorological indicators do show a good correspondence with drought disasters (as identified by relief payments), both temporally and spatially in Sri Lanka. Drought relief payment histories largely coincided with histories of major meteorological drought over a 40-year period. Although the meteorological drought indices employed were based solely on precipitation, statistically significant relationships were found between the number of drought relief payments made (a proxy for drought risk) and temporal variations of 6and 9-month accumulated rainfall anomaly indices.

Similarities in the spatial patterns of the total number of (weighted) drought payments made at the district level and meteorological drought occurrence over a 
(a)

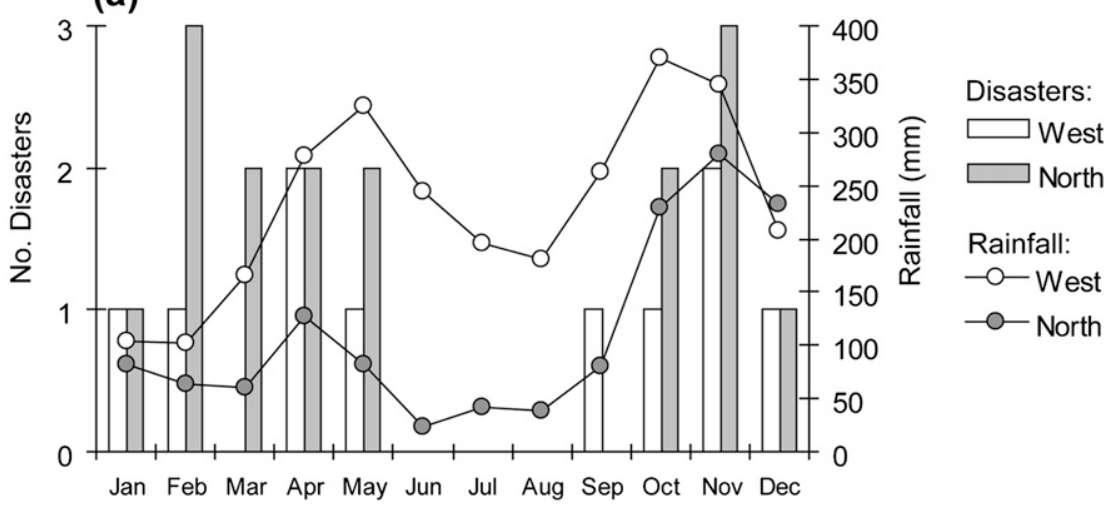

(b)

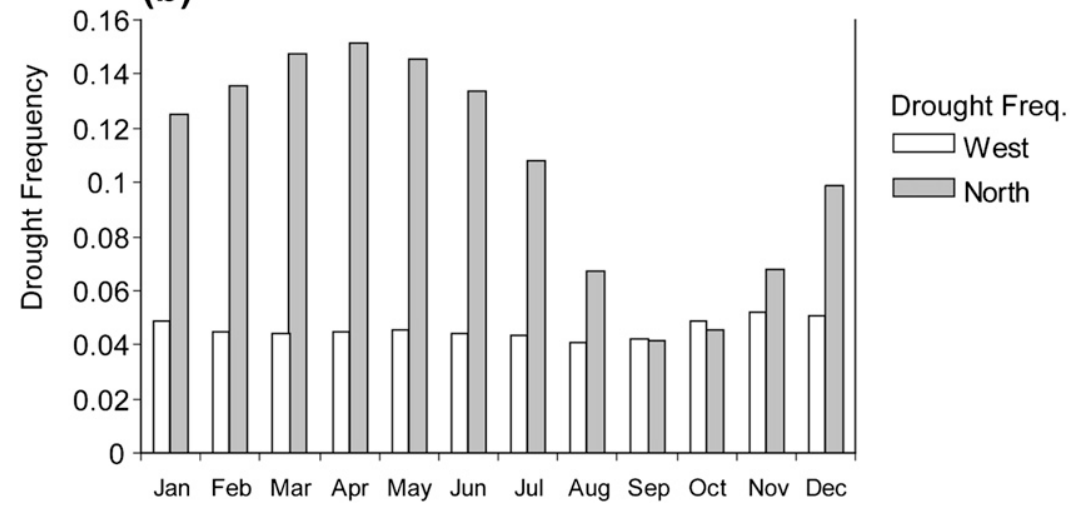

FIG. 8. (a) The number of drought relief payments made to districts in the northern and western climate zones (1960-2000) along with climatological average monthly rainfall. (b) The relative frequency of meteorological drought conditions, by month, for both regions based on runs of the PRCT-9 index seen in Fig. 6.

41-yr period were also found, although a few discrepancies were identified that can be attributed to political or fiscal considerations. The explicit relationship between drought relief payments and associated rainfall anomaly variations suggests that drought relief payments do not appear to be unduly dominated by these considerations.

A close correspondence between meteorological drought indicators and relief payments was found across regions of heterogeneous climate types with annual rainfall ranging from 500 to $5500 \mathrm{~mm}$ and rainfall seasonality ranging from unimodal to bimodal. That the closest correspondence was with 6- or 9-month meteorological drought indices also indicates the most relevant "time scale" of drought (in the context of relief payment occurrence) is for a period that exceeds the typical 3-month peaks in seasonal rainfall (e.g., MarchMay or October-December, as seen in the histograms of Fig. 1).

The overall results could be useful for local authorities as well as for relief organizations concerned with drought risk management and policy making. These results also suggest that drought monitoring can be useful in mitigating drought impacts if updated information is made available to users in near-real time. Such drought monitoring efforts are viable through in situ observations or high-resolution satellite rainfall estimates that have more recently become available for tropical regions, including Sri Lanka. In addition, seasonal climate predictions are now routinely available with a season (or more) lead time (e.g., Barnston et al. 2003). These seasonal rainfall predictions can be used to develop seasonal drought predictions that can be incorporated into a drought hazard early warning system.

The success in identifying drought relief payments based on rainfall indices in Sri Lanka provides encouragement for similar analyses in other tropical locations. Among the factors to be considered are spatial variations in regional climate and local vulnerability and resiliency to drought, which will vary depending on the extent to which mitigation measures and adaptive 
strategies have been implemented. Multiple drought indicators should be tested given the likely importance of seasonality and drought duration on the particular impact(s) of interest.

Acknowledgments. Samitha Jayamaha provided invaluable assistance in locating the data used in this study. Benno Blumenthal, Michael Bell, John Del Corral, Ruvini Perera, and Upamala Tennakoon helped with the analysis. Part of this work was supported by the Global Natural Disaster Hotspots project administered by the Center for Hazards and Risk Research of the Columbia Earth Institute and by the International Research Institute for Climate and Society from July to December 2003. This paper is funded in part by the National Oceanic and Atmospheric Administration through Grants NA050AR4311004 and NA03OAR4310161. The views expressed herein are those of the authors and do not necessarily reflect the views of NOAA or any of its subagencies.

\section{REFERENCES}

Barnston, A. G., S. J. Mason, L. Goddard, D. G. DeWitt, and S. E. Zebiak, 2003: Multimodel ensembling in seasonal climate forecasting at IRI. Bull. Amer. Meteor. Soc., 84, 1783-1796.

Cressman, G. P., 1959: An operational objective analysis system. Mon. Wea. Rev., 87, 367-374.

Department of Census and Statistics, 2001: Statistical abstract of the Democratic Socialist Republic of Sri Lanka. Department of Census and Statistics, Colombo, 423 pp.

Domroes, M., 1978: Aspects of aridity and drought in the monsoon climate of Sri Lanka. Indian J. Meteor. Hydrol. Geophys., 29, 384-394.

Heim, R. R., 2002: A review of twentieth-century drought indices used in the United States. Bull. Amer. Meteor. Soc., 83,11491165 .

Keyantash, J., and J. A. Dracup, 2002: The quantification of drought: An evaluation of drought indices. Bull. Amer. Meteor. Soc., 83, 1167-1180.

Lyon, B., 2004: The strength of El Niño and the spatial extent of tropical drought. Geophys. Res. Lett., 31, L21204, doi:10.1029/ 2004GL020901.

— , and A. G. Barnston, 2005: ENSO and the spatial extent of interannual precipitation extremes in tropical land areas. J. Climate, 18, 5095-5109.

Madduma Bandara, C. M., 1981: Effectives of drought on the livelihood of peasant families in the dry zone of Sri Lanka: A study of the Maha Patana Korale in north central province. Climatological Notes, No. 30, University of Tsukuba, Tsukuba, Japan, 46-58.

Malmgren, B. A., R. Hullugalla, G. Lindeberg, Y. Inoue, Y. Hayashi, and T. Mikami, 2007: Oscillatory behavior of monsoon rainfall over Sri Lanka during the late 19th and 20th centuries and its relationships to SSTs in the Indian Ocean and ENSO. Theor. Appl. Climatol., 89, 115-125.
McKee, T. B., N. J. Doesken, and J. Kleist, 1993: The relationship of drought frequency and duration to time scales. Preprints, Eighth Conf. on Applied Climatology, Anaheim, CA, Amer. Meteor. Soc., 179-184.

Nexant, cited 2008: Economic impact of poor power quality on industry in Sri Lanka. USAID. [Available online at http:// pdf.usaid.gov/pdf_docs/PNACU656.pdf.]

Palmer, W. C., 1965: Meteorological drought. U.S. Weather Bureau Research Paper 45, 58 pp.

Panabokke, C. R., 1996: Soils and agro-ecological environments of Sri Lanka. Natural Resources, Energy and Science Authority of Sri Lanka, Colombo, Sri Lanka, 220 pp.

Peiris, T. S. G., J. Hansen, and L. Zubair, 2008: Use of seasonal climate information to predict coconut production in $\mathrm{Sr}$ Lanka. Int. J. Climatol., 28, 103-110.

Peterson, T. C., and Coauthors, 1998: Homogeneity adjustments of in-situ atmospheric climate data: A review. Int. J. Climatol., 18, 1493-1517.

Puvaneswaran, K. M., and P. A. Smithson, 1993: An objective classification of homogeneous rainfall regimes in Sri Lanka. Theor. Appl. Climatol., 47, 105-115.

Rasmusson, E. M., and T. H. Carpenter, 1983: The relationship between eastern equatorial Pacific sea surface temperatures and rainfall over India and Sri Lanka. Mon. Wea. Rev., 111, 517-528.

Ropelewski, C. F., and C. K. Folland, 2000: Prospects for the prediction of meteorological drought. Drought: A Global Assessment, Vol. 1, D. Wilhite, Ed., Routledge, 21-40.

Sheskin, D. J., 2004: Parametric and Nonparametric Statistical Procedures. 3rd ed. Chapman and Hall, 1193 pp.

Smith, T. M., and R. W. Reynolds, 2004: Improved extended reconstruction of SST (1854-1997). J. Climate, 17, 2466-2477.

Suppiah, R., 1988: Relationships between the Indian Ocean sea surface temperatures and the rainfall of Sri Lanka. J. Meteor. Soc. Japan, 66, 103-112.

, 1996: Spatial and temporal variations in the relationships between the Southern Oscillation phenomenon and the rainfall of Sri Lanka. Int. J. Climatol., 16, 1391-1408.

_ and M. M. Yoshino, 1984: Rainfall variation of Sri Lanka. Part 2. Regional fluctuation. Arch. Meteor. Geophys. Biocl. 35B, 81-92.

Wilhite, D. A., 2000: Drought: A Global Assessment. Vol. 1. Routledge, $396 \mathrm{pp}$.

Wilks, D. S., 1995: Statistical Methods in the Atmospheric Sciences. Academic Press, 467 pp.

Zubair, L., 2002: El Niño influences on rice production in Sri Lanka. Int. J. Climatol., 22, 249-260.

_ 2005: Modernization of Sri Lanka's traditional irrigation system and sustainability. Sci. Technol. Soc., 10, 161-195.

_, and C. F. Ropelewski, 2006: The strengthening relationship between ENSO and the northeast monsoon rainfall over Sri Lanka and southern India. J. Climate, 19, 1567-1575.

_ S. A. Rao, and T. Yamagata, 2003: Modulation of Sri Lankan Maha rainfall by the Indian Ocean Dipole. Geophys. Res. Lett., 30, 1063, doi:10.1029/2002GL015639.

_ , V. Ralapanawe, U. Tennakone, Z. Yahiya, and R. Perera, 2006: Natural disaster risks in Sri Lanka: Mapping hazards and risk hotspots. Natural Disaster Hotspots Case Studies, M. Arnold et al., Eds., World Bank, 109-136.

-, M. Siriwardhana, J. Chandimala, and Z. Yahiya, 2008: Predictability of Sri Lankan rainfall based on ENSO. Int. J. Climatol., 28, 91-101. 